\title{
Reevaluation of the Prevalence of Metabolic Syndrome in an Urban Area of Turkey
}

\author{
Mehmet Emre Atabek, Beray Selver Eklioğlu, Nesibe Akyürek \\ Necmettin Erbakan University, School of Medicine, Department of Pediatric Endocrinology, Konya, Turkey
}

\section{ABSTRACT}

Objective: Our aim was to reveal a change in the prevalence of metabolic syndrome (MS) in the province of Konya in five years.

Methods: We studied 202 obese children and adolescents (body mass index $>95^{\text {th }}$ percentile) aged between 7 and 18 years. The diagnosis of impaired glucose tolerance, type 2 diabetes mellitus (T2DM), and MS were defined according to the modified World Health Organization criteria adapted for children.

Results: MS was found in $56.4 \%$ with a significantly higher rate among adolescents aged $12-18$ years $(63.2 \%)$ than among prepubertal children aged 7-11 years $(47 \%)(p=0.01)$. The prevalence figures for insulin resistance, glucose intolerance, and T2DM were 60, 8, and $2 \%$ among prepubertal children and $81.8,12.8$, and $0 \%$ among adolescents, respectively. The prevalence of fasting hyperinsulinemia in adolescents was significantly higher than in prepubertal children $(p<0.001)$. Hypertension was significantly more common in adolescents $(42.8 \%)$ than in prepubertal children $(32.9 \%)(p=0.04)$.

Conclusions: We found that the incidence of MS in the city center of Konya approximately doubled in the last five years with increased rates of morbidity and abnormal lipid profiles.

Key words: Childhood obesity, metabolic syndrome, insulin resistance, impaired glucose tolerance, type 2 diabetes

Conflict of interest: None declared

Received: 21.07 .2012

Accepted: 13.12 .2012

\section{Introduction}

Obesity is a chronic condition which impairs the quality of life in many ways. The prevalence of obesity in childhood today is more than 10 times compared to the 1970s. The World Health Organization (WHO) reported that overweight and obesity are responsible for $80 \%, 35 \%$, and $55 \%$ of cases of type 2 diabetes mellitus (T2DM), ischemic heart disease, and hypertension, respectively (1). Obesity is especially associated with insulin resistance, hyperinsulinemia, T2DM, and cardiovascular diseases (2).

Metabolic syndrome (MS) is one of the most important complications of obesity. MS is defined as a clinical condition intertwined with T2DM, cardiovascular disease, hypertension, dyslipidemia, and insulin resistance (3). Genetic and environmental factors also have a role in its development. MS increases the risk of T2DM fivefold and the risk of coronary heart disease twofold (4).

MS prevalence varies according to diagnostic criteria and populations. According to the NHANES III survey covering the period of 1988-1994, the prevalence of MS was $28.7 \%$ in obese adolescents in the United States of America (5). In Turkey, MS prevalence was reported to vary between 2.2 and $20 \%$ in childhood $(6,7)$. In a previous study (8), we found the MS prevalence as $27.2 \%$ in children and adolescents.

Our aim in this study was to determine the prevalence of MS in the urban area of Konya and to compare the results with previous findings.

\section{Methods}

Two hundred and two children (105 females and 97 males, aged $11.65 \pm 3.11$ years), who presented to the outpatient clinic 
of the Department of Pediatric Endocrinology and Diabetes at Necmettin Erbakan University Research Center in Konya, Turkey with the complaint of obesity, were included in our study. The children were required to meet the following inclusion criteria: (1) age, 7-18 years; (2) body mass index (BMI), greater than the 95th percentile for age and gender, according to the standards of the Centers for Disease Control and Prevention; (3) absence of a prior major illness, including type 1 or 2 diabetes, or of a condition known to influence body composition, insulin action, or insulin secretion; 4) absence of a history of medication known to influence metabolism such as glucocorticoid therapy. Informed consent and assent were obtained from all parents and children, respectively.

Each child underwent a complete physical examination, including anthropometric measures. Their pubertal development stages were assessed by a single pediatric endocrinologist using the criteria of Tanner. Height and weight were measured with an empty bladder in post-absorptive conditions. Height was measured to the nearest $0.5 \mathrm{~cm}$ on a standard height board. Weight was determined to the nearest $0.1 \mathrm{~kg}$ on a standard physician's beam scale with the subject dressed only in light underwear and no shoes. BMI was calculated as weight (in kilograms) divided by height (in meters) squared. Waist circumference was measured at the level of the umbilicus with the patient in the standing position and breathing normally. Hip circumference was measured at the level of the iliac crest. Blood pressure was measured with a standard mercury sphygmomanometer after the subjects had rested for at least $10 \mathrm{~min}$.

An oral glucose tolerance test (OGTT) was performed in 128 of these obese children and adolescents using a dose of 1.75 $\mathrm{g} / \mathrm{kg}$ body weight (to a maximum of $75 \mathrm{~g}$ ). The initial venous blood samples were obtained in the morning by venipuncture after overnight fasting. Subsequent samples were taken at $0,30,60,90$, and 120 minutes after glucose loading. Plasma glucose and plasma insulin levels were determined in these samples: plasma glucose by the glucose oxidase method and plasma insulin using IMMULITE immunoassay (IMMULITE Diagnostic Products Corporation, Los Angeles, CA). Plasma concentrations of total cholesterol, triglycerides, low-density lipoprotein (LDL)-cholesterol and high-density lipoprotein (HDL)-cholesterol were also measured in the initial samples using routine enzymatic methods with an Olympus 2700 Analyzer (Olympus Diagnostica $\mathrm{GmbH}$, Ireland).

Criteria for abnormal glucose homeostasis were defined according to the modified WHO criteria adapted for children (9). The corresponding categories, when the OGTT is used, are the following: normal glucose tolerance is defined as a 2-hour post-load glucose (2 hour PG) level of $<140 \mathrm{mg} / \mathrm{dL}$ ( $<7.8 \mathrm{mmol} / \mathrm{L})$; impaired glucose tolerance (IGT) as a 2 hour PG level between $140 \mathrm{mg} / \mathrm{dL}(7.8 \mathrm{mmol} / \mathrm{L})$ and $200 \mathrm{mg} / \mathrm{dL}$ $(<11.1 \mathrm{mmol} / \mathrm{L})$, and a diabetic state as a 2 hour PG $\geq 200 \mathrm{mg} /$
$\mathrm{dL}(\geq 11.1 \mathrm{mmol} / \mathrm{L})$. Following American Diabetes Association recommendations, a fasting glucose $\geq 110 \mathrm{mg} / \mathrm{dL}$ is defined as imparied fasting glucose (IFG) and $\geq 126 \mathrm{mg} / \mathrm{dL}$ ( $\geq 7.0 \mathrm{mmol} / \mathrm{L})$ as diabetes.

Homeostasis model assessment of insulin resistance (HOMA-IR; fasting insulin $x$ fasting glucose/22.5), which correlate with estimates of insulin resistance measured by the euglycemic clamp technique, was used as an index of insulin resistance (10). Insulin resistance is defined as HOMA-IR of greater than 3.16 according to our previously published data (11). Hyperinsulinism was defined from norms for pubertal stage: prepubertal $>15 \mathrm{mU} / \mathrm{L}$ and midpuberty (stages 2-4) $>30 \mathrm{mU} / \mathrm{L}$ (12). Fasting glucose/insulin ratio was calculated as fasting glucose concentration (mg/dL) /fasting insulin concentration $(\mu \mathrm{U} / \mathrm{mL})$. Quantitative insulin sensitivity check index was calculated as $1 /$ [(log fasting insulin concentration $(\mu \mathrm{U} / \mathrm{mL})+\log$ fasting glucose concentration (mg/dL)] (13).

MS was defined according to the WHO criteria adapted for children, a definition which requires three or more of the following components (14).

(1) Obesity: $\mathrm{BMI}>95^{\text {th }}$ percentile for age and sex.

(2) Abnormal glucose homeostasis: Any of the following (a) fasting hyperinsulinemia; (b) IFG; (c) IGT.

(3) Hypertension: Systolic blood pressure $>95^{\text {th }}$ percentile for age and sex.

(4) Dyslipidemia: Any of the following (a) high triglycerides (>105 mg/dL (>1.2 mmol/L) in children <10 years of age, and $>136 \mathrm{mg} / \mathrm{dL}(>1.5 \mathrm{mmol} / \mathrm{L})$ in children $\geq 10$ years of age); (b) low HDL-cholesterol $(<35 \mathrm{mg} / \mathrm{dL}(<0.9 \mathrm{mmol} / \mathrm{L}))$; (c) high total cholesterol ( $>95^{\text {th }}$ percentile).

\section{Statistical Analysis}

Data were expressed as mean \pm standard deviation. IGT, insulin resistance, T2DM and MS prevalence rates according to the prepubertal and pubertal groups were estimated by chisquare and Fisher tests. The differences between data were estimated using the student's t-test. Statistical significance was taken as $p<0.05$. All statistical analyses were performed using the Statistical Package for Social Sciences (SPSS/ Windows Version 11.0, SPSS Inc. Chicago, IL, USA).

\section{Results}

A total of 202 children and adolescents aged 7-18 years (85 prepubertal and 117 pubertal) underwent assessment. Mean age was $11.65 \pm 3.11$ years. The clinical characteristics of the study population are given in Table 1.

According to our results from OGTT performed in 128 obese children and adolescents, insulin resistance (HOMA-IR $>3.16$ ) was observed in $72.2 \%$, IFG in $4.4 \%$, and IGT in $10.9 \%$.

MS, defined as presence of $\geq 3$ components, was found in 114 subjects $(56.4 \%)$, with a significantly higher rate among pubertal subjects $(63.2 \%)$ than among prepubertal subjects $(47 \%)(p=0.01)$. There were no significant differences in the 
prevalence of MS by gender. Table 2 shows the prevalence of individual components of cardiovascular risk factors and MS by pubertal status.

In the present study, the prevalences of IR, IFG and IGT were $60 \%, 5.8 \%$ and $8 \%$ in the prepubertal age group and
Table 1. Clinical characteristics of the study population

\begin{tabular}{llll}
\hline & Prepubertal & Pubertal & P \\
\hline $\mathrm{N}$ & 85 & 117 & \\
Sex (F/M) & $52 / 33$ & $53 / 64$ & \\
Age (years) & $8.78 \pm 2.01$ & $13.74 \pm 1.86$ & $\mathrm{p}<0.001$ \\
BMI (kg/m²) & $26.06 \pm 3.54$ & $30.97 \pm 4.34$ & $\mathrm{p}<0.001$ \\
BMI-SDS & $2.23 \pm 0.51$ & $2.09 \pm 0.31$ & $\mathrm{p}=0.017$ \\
Waist hip ratio & $1.16 \pm 0.15$ & $0.91 \pm 0.08$ & $\mathrm{p}=0.09$ \\
Systolic blood & $113.75 \pm 17.65$ & $127.04 \pm 16.7$ & $\mathrm{p}<0.001$ \\
pressure (mmHg) & & & \\
Diastolic blood & $73.04 \pm 12.68$ & $76.92 \pm 13.15$ & $\mathrm{p}=0.047$ \\
pressure (mmHg) & & & \\
Total cholesterol (mg/dL) & $176.65 \pm 40.03$ & $171.86 \pm 37.3$ & $\mathrm{p}=0.38$ \\
Triglycerides $(\mathrm{mg} / \mathrm{dL})$ & $107.52 \pm 72.35$ & $122.57 \pm 73.12$ & $\mathrm{p}=0.15$ \\
HDL-cholesterol (mg/dL) & $44.27 \pm 11.7$ & $41.89 \pm 11.46$ & $\mathrm{p}=0.157$ \\
LDL-cholesterol (mg/dL) & $111.14 \pm 40.9$ & $104.21 \pm 35.02$ & $\mathrm{p}=0.20$ \\
Fasting glucose $(\mathrm{mg} / \mathrm{dL})$ & $91.26 \pm 9$ & $87.55 \pm 10.68$ & $\mathrm{p}=0.01$ \\
Fasting insulin $(\mu \mathrm{U} / \mathrm{mL})$ & $13.05 \pm 8.6$ & $19.67 \pm 13.86$ & $\mathrm{p}<0.001$ \\
HOMA-IR & $3.15 \pm 2.25$ & $4.1 \pm 2.7$ & $\mathrm{p}=0.007$ \\
QUICK-I & $0.32 \pm 0.032$ & $0.31 \pm 0.025$ & $\mathrm{p}=0.001$ \\
FGIR & $9.47 \pm 5.56$ & $6.11 \pm 3.25$ & $\mathrm{p}<0.001$ \\
\hline BMI-SDS: body $\mathrm{mass}$ (nd & & &
\end{tabular}

BMI-SDS: body mass index-standard deviation score, HDL: high-density lipoprotein, LDL: low-density lipoprotein, HOMA-IR: homeostasis model assessment for insulin ratio, QUICK-I: quantitative insulin sensitivity check index, FGIR: fasting glucose/insulin ratio
$81.1 \%, 3.4 \%$ and $12.8 \%$ in the pubertal age group, respectively. The differences in the rates of IR between prepubertal and pubertal children were significant, whereas the differences in IFG and IGT were not significant $(p<0.001,=0.41$ and $=0.56$, respectively). The prevalence of T2DM was $2 \%$ among the prepubertal group. Hyperinsulinemia was also more frequent in pubertal children $(27.3 \%$ vs. $14.1 \%$; $p<0.001)$. Hypertension was significantly more common in adolescents $(47.8 \%)$ than in prepubertal children $(32.9 \%)$ with obesity $(p=0.04)$. Overall dyslipidemia was identified in prepubertal and pubertal groups as $52.9 \%$ and $51.2 \%$, respectively, with no significant differences $(p=0.86)$. High total serum cholesterol concentrations were noted in $92.8 \%$, high serum triglyceride concentrations in $29.4 \%$ and low HDL in $23.1 \%$ of the prepubertal subjects. In the pubertal age group, high total serum cholesterol concentration was found in $92.9 \%$, high serum triglyceride concentration in $30.4 \%$ and low HDL in $26.5 \%$ of the subjects. Comparison of previous and current data was shown in Figure 1.

\section{Discussion}

It is known that obesity is a global problem and leads to increased morbidity and mortality. Many studies report an increased prevalence of glucose abnormalities and especially MS in obese children. Different prevalence figures for glucose abnormalities and MS in obese children were reported from in the prevalence of MS in the province of Konya in the past five years.

Although the prevalence figures differ by diagnostic criteria, the overall prevalence of MS in children is estimated to be $3-4 \%$ (15). According to Cizmecioglu et al (16), 38.8\% Turkey (8). In this present study, we aimed to reveal a change

Table 2. Prevalence of risk factors and metabolic syndrome by pubertal status
Prepubertal $n=85,(\%)$
Pubertal $n=117,(\%)$
p
Total $n=202,(\%)$

Hyperinsulinemia

Impaired glucose tolerance

Impaired fasting glucose

Dyslipidemia

Hypertension

Insulin resistance

Type 2 diabetes

Metabolic syndrome

AUC glucose (mg/dLx120 min)

AUC insulin $(\mu \mathrm{U} / \mathrm{mL} \times 120 \mathrm{~min})$

\section{$12(14.1)$}

$4(8)(n=50)$

$5(5.8)$

45 (52.9)

28 (32.9)

51 (60)

$1(2)(n=50)$

40 (47)

\section{2 (27.3)}

$10(12.8)(\mathrm{n}=78)$

4 (3.4)

60 (51.2)

56 (47.8)

95 (81.1)

0 ( $\mathrm{n}=78$ )

74 (63.2)

$\begin{array}{ll}\mathrm{p}<0.001 & 44(21.7) \\ \mathrm{p}=0.56 & 14(10.9)(\mathrm{n}=128) \\ \mathrm{p}=0.41 & 9(4.4) \\ \mathrm{p}=0.86 & 105(51.9) \\ \mathrm{p}=0.04 & 84(41.5) \\ \mathrm{p}<0.001 & 146(72.2) \\ \mathrm{p}=0.39 & 1(0.7)(\mathrm{n}=128) \\ \mathrm{p}=0.01 & 114(56.4) \\ \mathrm{p}=0.64 & \\ \mathrm{p}=0.05 & \end{array}$




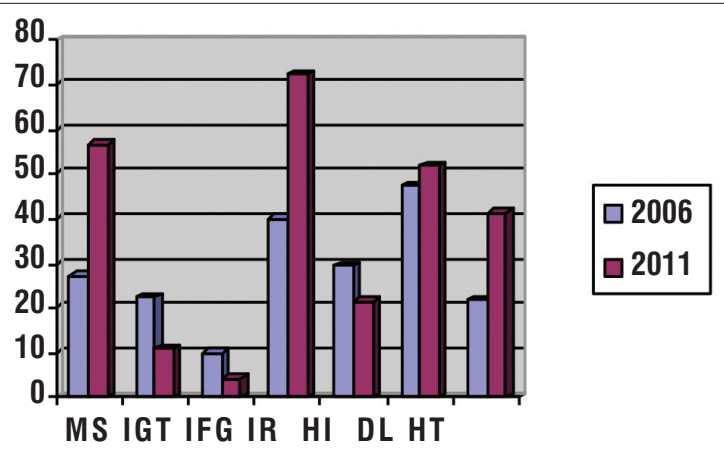

Figure 1. Prevalence of MS and of its components in obese children and adolescents

MS: metabolic syndrome, IGT: impaired glucose tolerance, IFG: impaired fasting glucose, IR: insulin resistance, HI: hyperinsulinemia, DL: dyslipidemia, HT: hypertension

of obese children in Turkey were diagnosed as having MS. Isomaa et al (17) found this prevalence to be $42 \%$ (17). According to the results of Cook et al (5), the prevalence of the MS in adolescents was $28.7 \%$. The gross prevalence of the MS in the USA obese population was 30\% after ageadjustment (18). We found $47 \%(40)$ of obese children and $63.2 \%$ (74) of adolescents, $56.4 \%$ (114) of all patients to have evidence of MS as defined above by the presence of three of the following components: obesity, abnormal glucose homeostasis, dyslipidemia and hypertension.

Five years ago, we found MS prevalence as 27.2 in obese prepubertal children and $37.6 \%$ in obese adolescents (8). According to our data, we found that the prevalence of MS had increased both in the prepubertal and pubertal group, and the prevalence had doubled in five years. We attribute this increase to changes in lifestyle and nutrition behaviors and spending more time in front of television and computer screens.

The development of T2DM requires both IR and inadequate insulin secretion, leading to persistent hyperglycemia. IR in the young has been reported in a variety of ethnic groups and is strongly associated with obesity $(19,20)$. The stress of obesity and the increased demand for insulin at the time of adolescence explain the largely pubertal and postpubertal onset of type 2 diabetes in children. Insulin sensitivity decreases by $30 \%$ during puberty with compensatory increase in insulin secretion (21). In our study, the rate of differences of IR in the prepubertal and pubertal stages was significant and more prevalent among obese adolescents. IR was increased in both prepubertal and pubertal groups as compared to our previous data (9). All insulin sensitivity indices were significantly high in the pubertal group.

Glucose metabolism disorders secondary to obesity are initiated in childhood. In a study from Spain, the prevalence of IGT in obese children and adolescents was $7.4 \%$. There were no children with T2DM; however, the prevalence of IR in obese children studied was 35.8\% (22). Wabitsch et al (23) determined the prevalence of T2DM in $1.5 \%$ of the patients and impaired glucose regulation in $2.1 \%$ of the patients in a large group of Caucasian children and adolescents with obesity. Wiegand et al (24) found that $2.4 \%$ of their obese pediatric patients had IGT. In an Italian study, the prevalence rates of T2DM and IGT were 0.1 and $4.5 \%$, respectively (25). In our study, we found that 14 (10.9\%) patients had IGT and $1(0.7 \%)$ patient was diagnosed with T2DM. It is reported that the prevalence of IGT is not influenced by obesity but related to poor beta-cell function that shows signs of deterioration with age (26). The evolution from normal to IGT is associated with IR and a failure of betacell insulin secretory capacity, which deteriorates further as T2DM develops (27). Our findings of a high prevalence of IGT and IR but a low prevalence of T2DM reflect the range of abnormalities of glucose homeostasis associated with obesity in childhood.

Elevated triglycerides and low levels of HDL-cholesterol characterize the dyslipidemia in MS. Increased triglycerides in the presence of IR and hyperinsulinemia result from increased circulating free fatty acids. As IR increases, the lipolysis inhibitory mechanisms of insulin on adipose tissue diminish and more free fatty acids are produced (28). In our study, total cholesterol and triglyceride serum concentrations were higher and HDL level was lower in both obese children and adolescents; however, the differences were not statistically significant. Dyslipidemia frequency was $51.9 \%$, which is higher according to our previous data and studies performed by Saha et al and Viner et al $(29,30)$.

The cause of hypertension in the MS is multifactorial and likely to be related to all the elements of the syndrome including obesity, IR, and dyslipidemia. Obesity may be the most important factor, but the other elements of the syndrome also play a role in creating and mediating the changes that ultimately result in hypertension (31). In our study, $41.5 \%$ of all patients had hypertension. Sorof et al (32) found the hypertension prevalence as $10.7 \%$ in obese children. However, increased figures (47-60\%) were reported for hypertension prevalence with ambulatory blood pressure monitoring (33). Although we took one measurement of blood pressure, we observed a high frequency. These findings show that preventing obesity is one of the important factors for the development of hypertension and related end-organ damage in early ages.

The prevalence of $I R$ is very high among obese children, but T2DM is yet to develop in this age group. In conclusion, the incidence of MS in the city center of Konya province approximately doubled over the last five years, and we found increased rates of morbidity. 


\section{References}

1. World Health Organization. The challenge of obesity in the WHO European Region and the strategies for response (1517 November). Istanbul 2006.

2. Goran MI, Ball GD, Cruz ML. Obesity and risk of type 2 diabetes and cardiovascular disease in children and adolescents. J Clin Endocrinol Metab 2003;88:1417-1427.

3. Khunti K, Davies M. Metabolic syndrome. BMJ 2005;331: $1153-1154$.

4. Sadikot SM, Misra A. The metabolic syndrome: An exercise in utility or futility? Diabetes Metab Syndr 2007;1:3-21.

5. Cook S, Weitzman $M$, Auinger $P$, Nguyen $M$, Dietz $\mathrm{WH}$. Prevalence of a metabolic syndrome phenotype in adolescents: findings from the third National Health and Nutrition Examination Survey, 1988-1994. Arch Pediatr Adolesc Med 2003;157:821-827.

6. Hatun S, Cizmecioglu F. Çocukluk çağında metabolik sendrom. Çocuk Sağlığı ve Hastalıkları Dergisi 2005;48:257-265.

7. Agirbasli M, Cakir S, Ozme S, Ciliv G. Metabolic syndrome in Turkish children and adolescent. Metabolism 2006;55:10021006.

8. Atabek ME, Pirgon O, Kurtoglu S. Prevalence of metabolic syndrome in obesse Turkish children and adolescents. Diabetes Res Clin Pract 2006;72:315-321. Epub 2005 Dec 1

9. Glucose tolerance and mortality: comparison of WHO and American Diabetic Association diagnostic criteria. The DECODE study group on behalf of the Europe an Diabetes Epidemiology Group: Collaborative Analysis of Diagnostic Criteria in Europe. Lancet 1999;354:617-621.

10. Conwell LS, Trost SG, Brown WJ, Batch JA. Indexes of insulin resistance and secretion in obese children and adolescents: a validation study. Diabetes Care 2004;27:314-319.

11. Keskin M, Kurtoglu S, Kendirci M, Atabek ME, Yazici C. Homeostasis model assessment is more reliable than the fasting glucose/insulin ratio and quantitative insulin sensitivity check index for assessing insulin resistance among obese children and adolescents. Pediatrics 2005;115:500-503. Epub 2005 Mar 1

12. Goran MI, Gower BA. Longitudinal study on pubertal insulin resistance. Diabetes 2001;50:2444-2450.

13. Katz A, Nambi SS, Mather K, Baron AD, Follmann DA, Sullivan G, Quon MJ. Quantitative insulin sensitivity check index: a simple, accurate method for assessing insulin sensitivity in humans. J Clin Endocrinol Metab 2000;85:2402-2410.

14. Alberti KG, Zimmet PZ. Definition, diagnosis and classification of diabetes mellitus and its complications. Part 1: diagnosis and classification of diabetes mellitus provisional report of a WHO consultation. Diabet Med 1998;15:539-553.

15. Weiss R, Dziura J, Burgert TS, Tamborlane WV, Taksali SE, Yeckel CW, Allen K, Lopes M, Savoye M, Morrison J, Sherwin RS, Caprio S. Obesity and the metabolic syndrome in children and adolescents. N Engl J Med 2004;350:2362-2374.

16. Cizmecioglu FM, Hatun S, Kalaca S. Metabolic syndrome in obese Turkish children and adolescents: comparison of two diagnostic models. Turk J Pediatr 2008;50:359-365.

17. Isomaa B, Almgren $P$, Tuomi $T$, Fors B, Lahti K, Nissen M, TaskınenMR, Groop L. Cardiovascular morbidity and mortality associated with metabolic syndrome. Diabetes Care 2001;24:683-689.
18. Cruz ML, Weigensberg MJ, Huang TT, Ball G, Shaibi GQ, Goran Ml. The metabolic syndrome in overweight Hispanic youth and the role of insulin sensitivity. J Clin Endocrinol Metab 2004;89:108-113.

19. Silink M. Childhood diabetes: a global perspective. Horm Res 2002;57(Suppl 1):1-5.

20. Weyer C, Tataranni PA, Bogardus C, Pratley RE. Insulin resistance and insulin secretory dysfunction are independent predictors of worsening of glucose tolerance during each stage of type 2 diabetes development. Diabetes Care 2001;24:89-94.

21. Kobayashi K, Amemiya S, Higashida K, Ishihara T, Sawanobori E, Kobayashi K, Mochizuki M, Kikuchi N, Tokuyama K, Nakazawa S. Pathogenic factors of glucose intolerance in obese Japanese adolescents with type 2 diabetes. Metabolism 2000;49:186-191.

22. Tresaco B, Bueno G, Moreno LA, Garagorri JM, Bueno M. Insulin resistance and impaired glucose tolerance in obese children and adolescents. J Physiol Biochem 2003;59:217223.

23. Wabitsch M, Hauner H, Hertrampf M, Muche R, Hay B, Mayer $H$, Kratzer W, Debatin KM, Heinze E. Type II diabetes mellitus and impaired glucose regulation in Caucasian children and adolescents with obesity living in Germany. Int J Obes Relat Metab Disord 2004;28:307-313.

24. Wiegand S, Maikowski U, Blankenstein O, Biebermann $H$, Tarnow P, Grüters A. Type 2 diabetes and impaired glucose tolerance in European children and adolescents with obesity -- a problem that is no longer restricted to minority groups. Eur J Endocrinol 2004;151:199-206.

25. Invitti C, Guzzaloni G, Gilardini L, Morabito F, Viberti G. Prevalence and concomitants of glucose intolerance in European obese children and adolescents. Diabetes Care 2003;26:118-124.

26. Goran MI, Bergman RN, Avila Q, Watkins M, Ball GD, Shaibi GQ, Weigensberg MJ, Cruz ML. Impaired glucose tolerance and reduced beta-cell function in overweight Latino children with a positive family history for type 2 diabetes. J Clin Endocrinol Metab 2004;89:207-212.

27. Gerich JE. Contributions of insulin-resistance and insulinsecretory defects to the pathogenesis of type 2 diabetes mellitus. Mayo Clin Proc 2003;78:447-456.

28. Menuet R, Lavie CJ, Milani RV. Importance and management of dyslipidemia in the metabolic syndrome. Am J Med Sci 2005;330:295-302.

29. Saha AK, Sarkar N, Chatterjee T. Health consequences of childhood obesity. Indian J Pediatr 2011;78:1349-1355. Epub 2011 Jun 10

30. Viner RM, Segal TY, Lichtarowicz-Krynska E, Hindmarsh P. Prevalence of the insulin resistance syndrome in obesity. Arch Dis Child 2005;90:10-14.

31. Morse SA, Zhang R, Thakur V, Reisin E. Hypertension and the metabolic syndrome. Am J Med Sci 2005;330:303-310.

32. Sorof JM, Lai D, Turner J, Poffenbarger T, Portman RJ. Overweight, ethnicity, and the prevalence of hypertension in school-aged children. Pediatrics 2004;113:475-482.

33. Maggio AB, Aggoun Y, Marchand LM, Martin XE, Herrmann $F$, Beghetti M, Farpour-Lambert NJ. Associations among obesity, blood pressure, and left ventricular mass. J Pediatr 2008;152:489-493. Epub 2007 Dec 21 